\title{
The Evolution of Project NANO: A Program that Enables Students to Explore in Real Time Several Crosscutting Concepts of the Next Generation Science Standards
}

\author{
Sherry L. Cady ${ }^{1}$, Mikel Blok ${ }^{2}$, Keith Grosse ${ }^{3}$, and Jennifer Wells ${ }^{4}$ \\ ${ }^{1}$ Pacific Northwest National Laboratory, Richland, WA USA \\ ${ }^{2}$ Beaverton High School, Beaverton, OR USA \\ ${ }^{3}$ Lake Oswego High School, Lake Oswego, OR USA \\ ${ }^{4}$ Center for Science Education, Portland State University, Portland, OR USA
}

The teacher professional development program known as Project NANO (Nanoscience and Nanotechnology Outreach) has more than 75 teachers in 8 different school districts that have given more than 7500 students in Portland area high school and middle school classrooms hands-on experience exploring the submicroscopic world with a research-grade scanning electron microscope (SEM). These students experience the same type of excitement and joy that every career microscopist has felt when they discover something new or unexpected with their microscope of choice. It's hard to imagine a more direct means to stimulate every student's sense of wonder about how and why natural and man-made materials function as they do than to allow students to use research-grade instruments to conduct their own inquiries and make their own discoveries. Project NANO students' explore several crosscutting concepts of the Next Generation Science Standards (NGSS) in real time with technology that illustrates how structure links with function, reveals hidden sub-microscopic patterns, and demonstrates when scale, proportion and quantity can affect a system's structure or performance. Project NANO students can deepen their understanding of the natural sciences and nanoscale concepts through inquiry projects.

While it's easy to understand how Project NANO students could increase their awareness of nanoscience by over 60\% and become aware of more STEM careers that involve using an SEM, the program has also increased rigor and the use of inquiry in the classroom. Project NANO workshops have evolved i) via the results of pre- and post-assessments, which demonstrate how directed and inquiry-based authentic research experiences impact student's attitudes toward (nano)science, and ii) through the use of resource folios, which support teachers' efforts to develop and scaffold lesson plans that incorporate the SEM and stereoscopes into authentic research experiences that reinforce their curriculum and reflect their unique teaching styles.

Workshops: Project NANO operates via a collaboration between high school teachers, educational researchers, university faculty and administrators, school districts and administrators, and funding partners that include a philanthropic donor and electron microscope manufacturers and representatives. Our teacher training workshops (one-week summer professional development courses for novice and veteran Project NANO teachers) enable in-service teachers to go back into their classroom with a well crafted unit that fits their needs. Middle school teachers in particular develop cross-curricular lessons as part of a forensics science unit that involves biology, chemistry, physics, and geology. Veteran Project NANO teachers refine their initial lesson plans by taking the more advanced workshop, which has led to highly vetted lesson plans for each of the natural sciences. We have modified our workshops to provide all participants with more time to learn how the SEM works, become proficient with the instruments and image analysis with freeware like Image J, and prepare written and oral lesson plans and presentations. As part of the workshops, the teachers themselves work through an inquiry process as they collect data and learn to use the SEM. Teachers build their lesson plans and vet them with other in-service teachers from different schools, pre-service teachers still involved in University Education studies, relatively new 
$\left(1^{\text {st }}-3^{\text {rd }} \mathrm{yr}\right)$ teachers, and with veteran (20-35 yrs) teachers via the workshops. This multi-tiered training format fosters and facilities new networks among teachers that enables them to develop a new community of practice among teachers in the Portland Metro Region. Each group brings value to the process as they share their experiences that resulted from use of the technology, the development of classroom pedagogy savvy, and by encouraging each other to teach with research-grade technology in the classroom. Veteran Project NANO teachers provide wise counsel for those early career teachers who are still developing strategies and grasping the depth of ideas they can share with their students about nanoscience. As a result of our integrated, multi-level workshop classrooms, Project NANO instructors are developing a growing collection of excellent next generation nanoscience/nanotechnology lessons.

Pre- and Post-Assessments: Project NANO teachers assign an on-line survey that asks students to selfevaluate their own experience and level of proficiency related to using microscopes and their interest in using the SEM to conduct research or as a possible career option. We found statistically significant (16\% on average) gains between the pre- and the post-survey results after just one exposure to a Project NANO lesson. The highest gains were linked to questions related to students' sense of proficiency in using both the SEM and a stereomicroscope (average 25\% increase) as well as their interest in pursuing future nanoscale science related learning experiences (21\% increase). As Project NANO has evolved over the past 6 years, its network of middle school and high school teachers has grown. In this way, some students can even be exposed to Project NANO in $7^{\text {th }}, 8^{\text {th }}$ and each year of high school. We hypothesize that the positive effect of Project NANO on student learning and awareness of possible STEM careers will increase even more as more students explore nanoscience concepts with the use of research-grade nanotechnology in sequential years in a variety of science classes.

Resource Folios: The use of Resource Folios has also informed program adaptations in subsequent years. We found that i) when the summer workshop teachers scored lower on their pre- and post-surveys and units of instruction, most often because those teachers had less experience working with nanoscale concepts, their average class grades were lower; ii) teachers who were the most experienced working with nanoscale concepts scored the highest on the pre- and post-surveys and exhibited the highest level of confidence working with the SEM during the summer workshops - their classes also had the highest learning outcomes; iii) the teachers who expressed the highest level of anxiety throughout the summer workshop planning period, classroom observations, and during the focus group interviews also reported the lowest average student grades; and iv) when student grades were triangulated with classroom observation and focus group data, we found that teachers with the largest class sizes struggled to engage all of the students consistently throughout the entire inquiry process.

We have found that summer workshops and academic year coaching positively supports teachers by enabling them to set their own well-reasoned learning goals, which also included extending their efforts to support student research in science competitions. Students are thrilled to work with leading edge technology and teachers are excited to improve student learning using technology. Project NANO has evolved in ways that "move the needle" by breaking new ground in teaching and learning in areas that cover cross-cutting concepts of the NGSS and with regard to the involvement and use of advanced technology and nanoscale concepts in science inquiry and authentic research experiences.

Support for Project NANO has come from the M.J. Murdock Charitable Trust, Portland State University, Nanoscience Instruments, Phenom-World., FEI Hillsboro, and SLC from the Environmental Molecular Sciences Laboratory, a DOE Office of Science User Facility sponsored by the Office of Biological and Environmental Research and located at PNNL. 